\title{
Geobotânica por sensoriamento remoto e aerogamaespectrometria aplicados ao mapeamento geológico da Amazônia: um estudo comparativo no vale do Guaporé (MT)
}

\author{
Mônica Mazzini Perrotta ${ }^{1}$, Teodoro Isnard Ribeiro de Almeida ${ }^{2}$, João Batista Freitas de Andrade ${ }^{3}$, \\ Carlos Roberto de Souza Filho ${ }^{4}$, Gilmar José Rizzotto ${ }^{5}$ \& Mauricio Guerreiro Martinho dos Santos ${ }^{2}$
}

\begin{abstract}
Resumo Em áreas de floresta tropical métodos indiretos de mapeamento baseados em sensoriamento remoto e em geofísica aeroportada são necessários para substanciar e expandir as informações geológicas de campo. A aerogamaespectrometria informa da radiação gama emitida pelas rochas e solos. As imagens de sensoriamento remoto óptico informam do comportamento espectral da vegetação, função da constituição química das folhas componentes do dossel da floresta e de sua arquitetura. O objetivo desse estudo é avaliar a correlação das variações da cobertura vegetal com a variação litológica em áreas na Amazônia brasileira através de dados do sensor multiespectral ASTER e dados gamaespectrométricos. Técnicas de processamento digital, visando o realce espectral de diferentes compostos foliares, e sua generalização através de filtro de convolução passabaixas, foram aplicados aos dados multiespectrais. Os dados gamaespectrométricos, após pré-processamento padrão, foram convertidos em imagens dos canais eU, eTh, K, distribuição ternária K-U-Th e razões. A comparação entre as imagens de sensoriamento remoto óptico e de gamaespectrometria mostrou uma importante correlação, em que pese as diferentes origens do sinal e dos comprimentos de onda envolvidos. Como a origem da radiação gama necessariamente é mineral demonstra-se tanto a importância da informação geológica presente no dossel florestal como a eficiência na estratégia de processamento digital utilizada.
\end{abstract}

Palavras-chave: sensoriamento remoto, geobotânica, aerogamaespectrometria, mapeamento geológico, sensor ASTER.

\begin{abstract}
Remote sensing geobotany and airborne gamma-ray data applied to geological mapping of the Amazon: a comparative study in the Guaporé Valley (Mato Grosso State, Brazil) This paper comprises a comparison between the vegetation response in ASTER multispectral optical imagery and possibly equivalent bedrock/regolith/soil response in airborne gamma-ray spectrometry grids, employing two tropical rainforest areas in the Brazilian Amazon as controls. The applied technique comprised band ratios using a fixed near infrared band (numerator) divided by individual visible and shortwave infrared bands (denominator). These band ratios were subsequently submitted to principal component analysis, and the high frequency information smoothed by low pass filtering. The color compositions selected for interpretation were sharpened by the first principal component of the original ASTER bands through an IHS transform in order to add albedo/ texture information - lost by band rationing - back to the imagery. The products show a plausible coherence with airborne gamma-ray data and field observations, proving that the proposed processing strategy applied to low cost multispectral data can provide useful geologic information in inaccessible vegetaded areas of the Amazon.
\end{abstract}

Keywords: remote sensing, geobotany, airborne gamma-ray, geological mapping, Advanced Spaceborne Thermal Emission and Reflection Radiometer.

INTRODUÇÃO Em áreas de floresta amazônica, dados de sensoriamento remoto orbital (disponíveis para todo o planeta e sem custo significativo) e de geofísica aeroportada (de disponibilidade restrita e alto custo) são, em geral, a melhor alternativa para substanciar e expandir espacialmente as escassas informações geológicas obtidas no campo.
A aerogamaespectrometria informa da radiação gama emitida pelas rochas e solos. Sua capacidade na discriminação da variação litológica em áreas densamente vegetadas vem sendo explorada há várias décadas, com inúmeros exemplos na literatura. Já as imagens de sensoriamento remoto óptico, informam, nestas áreas, do comportamento espectral da vegetação. Neste

1 - CPRM - Serviço Geológico do Brasil, Divisão de Sensoriamento Remoto (DISERE), São Paulo (SP), Brasil Brasil. E-mail: perrotta@sp.cprm.gov.br

2 - Instituto de Geociências, Universidade de São Paulo, São Paulo (SP), Brasil. E-mail: talmeida@usp.br, mauricioguerreiro@uol.com.br

3 - CPRM - Serviço Geológico do Brasil, Divisão de Geofísica (DIGEOF), Rio de Janeiro (RJ), Brasil. E-mail: jfreitas@rj.cprm.gov.br

4 - Instituto de Geociências, Universidade Estadual de Campinas/UNICAMP, Campinas (SP), Brasil. E-mail: beto@ige.unicamp.br

5 - CPRM - Serviço Geológico do Brasil, Residência de Porto Velho (REPO), Porto Velho (RO), Brasil. E-mail: gilmarizz@pv.cprm.gov.br 
caso é a constituição química das folhas componentes do dossel da floresta, e sua arquitetura, que determinam a porção da radiação de origem solar a ser refletida.

Os raios gama são radiação eletromagnética (REM) com comprimentos de onda em torno de $10^{-3}$ $\mathrm{nm}$, originada pelo decaimento dos isótopos radioativos $\mathrm{K}^{40}, \mathrm{Tl}^{208}(e \mathrm{Th})$ e $\mathrm{Bi}^{214}(e \mathrm{U})$ contidos em minerais. Já a REM refletida pelo dossel florestal e captada pelo sensor ASTER, em comprimentos de onda entre 400 e $2500 \mathrm{~nm}$, tem origem solar.

Os dados aerogeofísicos são essenciais para estudos geológicos em áreas ínvias, já que as assinaturas radiométricas podem contribuir na discriminação litogeoquímica do substrato rochoso e das formações superficiais. Entretanto, durante intemperismo químico ou físico os radioelementos contidos nas rochas podem ser remobilizados, redistribuídos e incorporados no regolito, podendo diferir substancialmente das rochas do substrato (Wilford et al. 1997). Entretanto, Martelet et al. (2006) observaram em área de floresta equatorial na Guiana Francesa que os raios gama emitidos são relacionados primariamente à mineralogia e à geoquímica das rochas e, apenas secundariamente, aos materiais intempéricos, incluindo-se o regolítico. Estes autores constataram também que o problema da atenuação da emissão da radiação gama pela absorção de parte do sinal por florestas densas é ainda menos importante, uma vez que há forte preservação das variações de sinal relacionadas à geologia, permitindo sua interpretação.

A variação nas características da vegetação, em consonância a variações geológicas do substrato (geobotânica), já foi objeto de investigação por Agricola (1556), que descreveu senescência precoce e nanismo de plantas crescidas sobre depósitos metálicos. Em sua completa revisão sobre a geobotânica, Ustin et al. (1999) citam os primeiros estudos sistemáticos que demonstraram a influência da litologia, depósitos minerais, e fraturamento dos corpos rochosos nas características da vegetação (e.g. Chikishev 1965, Cannon 1960, 1971 e Brooks 1972). Outro trabalho relevante na compreensão das relações geobotânicas é o de Mouat (1982), que divide a resposta da vegetação, em relação às condições geoquímicas, em fatores estruturais (alterações na fisiologia) e fatores taxonômicos (conjunto das espécies). Tais alterações na cobertura vegetal ocorrem associadas a solos e rochas distintos, relacionados ou não a depósitos minerais, como demonstrado por Sztutman e Rodrigues (2002) no Parque Estadual da Campina do Encantado (PECE), município de Pariquera-Açu (SP) e Godoy (2001) que encontrou duas florestas não similares em fragmentos de Mata Atlântica secundária sobre calcários e filitos no Alto Ribeira (SP). Botrel et al. (2002) indicaram uma notável influência de solos e topografia na florística e estrutura de floresta estacional semidecídua no Estado de Minas Gerais, tal como Almeida et al. (2007a), que identificaram diferenças florísticas e fisionômicas relacionadas à presença de alteração hidrotermal em rochas da Formação Serra da Pedra Preta, Grupo Serra do Itaberaba, São Paulo.

A necessidade de acurada análise da vegetação e conhecimentos de botânica foi uma das causas da geobotânica não ter se tornado operacional como técnica na prospecção mineral e mapeamento geológico (Brooks 1972). Uma forte limitação no seu desenvolvimento está ligada à imprevisibilidade das correlações entre as características da vegetação e as do substrato, normalmente determinadas empiricamente, para situações locais e específicas, e, portanto de difícil generalização (Ustin et al. 1999).

Com o desenvolvimento do sensoriamento remoto óptico multiespectral abriu-se a perspectiva de reconhecimento de zonas tonalmente homólogas em imagens processadas para realce da variação da cobertura vegetal. Estimulou ainda investigações no sentido de se determinar padrões de reflectância foliar e suas anomalias associadas à toxidade mineral (e.g. Raines et al. 1978, Talvitie 1979, Horler et al. 1980, Milton 1983 e Collins et al. 1983). Mas o problema da aplicação de anomalias de reflectância em dados de imagem é que as propriedades ópticas da vegetação dependem não apenas de variações na constituição química foliar, mas também da distribuição espacial e estrutura anatômica das folhas, da idade das plantas, disponibilidade de água, arquitetura do dossel e até de fatores não intrínsecos, como relevo (Ustin et al. 1999, Almeida 2005). Assim acredita-se que o tipo de processamento digital adequado à identificação de discretas variações nas coberturas vegetais não deva privilegiar a busca de padrões espectrais, mas sim uma abordagem sistêmica da cobertura vegetal, observando-se o maior número possível de parâmetros (Almeida \& Souza Filho 2004; Almeida 2005; Almeida et al. 2006).

Desta forma, fundamentando-se nestas experiências anteriores e em vista da urgente necessidade de dados geológicos na vasta região coberta por floresta tropical, este estudo compreende uma avaliação da correlação das variações nas propriedades espectrais da cobertura vegetal com a variação litológica em duas áreas na Amazônia brasileira através de dados do sensor ASTER. Para tanto, dados de campo foram utilizados como balizadores dos resultados bem como dados aerogamaespectrométricos, cuja fonte é necessariamente mineral.

GEOLOGIA DA ÁREA DE ESTUDO A área de estudo localiza-se no Vale do Guaporé (MT), na Folha Pimenteiras do Oeste 1:250.000, ora em fase de mapeamento geológico pela CPRM (Rizzotto 2006). Para aplicação da técnica empregada de realce da variação da cobertura vegetal em imagem multiespectral é necessário que a área trabalhada contenha apenas vegetação original preservada (Almeida 2005). Dessa forma, foram selecionadas para estudo duas áreas densamente vegetadas, praticamente inacessíveis, dentro das Terras Indígenas Lagoa dos Brincos (área 1) e Vale do Guaporé (área 2) (Fig. 1). Interesses minerários nestas áreas consistem de ouro (ambas) e minério de cobre (Vale do Guaporé) (Ricardo \& Rolla 2005).

Na região, segundo Rizzotto (2006), depósitos sedimentares do Neógeno, Cretáceo e Paleozóico, têm como embasamento, de idade ectasiana, uma asso- 
ciação de rochas metamáficas e metaultramáficas, de afinidade N-MORB, com intercalações de formações ferríferas bandadas e manganesíferas e de gnaisses calcissilicáticos. Depósitos de níquel ocorrem em corpos de serpentinito e ocorrências localizadas de platinóides associam-se a metabásicas. Compreende ainda o embasamento uma extensa associação de xistos e paragnaisses. Intrusões de granitóides calcialcalinos de alto potássio, representados por titanita-biotita monzogranitos, granodioritos e subordinadamente tonalitos, são sin a tardi-tectônicas na evolução de uma orogênese intracontinental mesoproterozóica, que provocou deformação e metamorfismo das rochas no grau médio. Sieno e monzogranitos a biotita e granada marcam as fases finais do magmatismo e da deformação em torno de 1320 M.a.. Este conjunto foi atribuído em Brasil/ DNPM (1979) ao Complexo Xingu. O regolito na área é areno-argiloso rico em minerais de potássio (k-feldspato e muscovita).

CLIMA, VEGETAÇÃO E SOLO NA ÁREA DE ESTUDO A região do Vale do Guaporé posiciona-se na transição entre os climas equatorial e tropical caracterizando-se por três a quatro meses secos (de junho a setembro) com chuvas de verão, temperatura média do mês mais frio de aproximadamente $23^{\circ} \mathrm{C}$ e precipitação anual média de $2150 \mathrm{~mm}$ (Brasil/DNPM 1979).

A área 1 de estudo (Fig. 1) insere-se totalmente em ambiente fitogeográfico de floresta estacional semidecidual submontana de dossel emergente (IBGE 1992, 2004, online) desenvolvida em áreas pré-Cambrianas do Complexo Xingu, sobre argissolo vermelho-amarelo eutrófico (IBGE 2007) ou ainda sobre afloramentos rochosos (Brasil/DNPM 1979). Segundo informações descritas no projeto RADAMBRASIL (Brasil/DNPM 1979) esta unidade fitogeográfica é caracterizada pela estacionalidade da folhagem das árvores mais altas com $20 \%$ a $50 \%$ de folhas secas no período de estiagem, embora grande parte possua folhagem sempre verde, juntamente com os arbustos e pequenas árvores da submata. Forma um dossel semicompacto cujo estrato superior, de indivíduos de copas frondosas e fustes linheiros, contém árvores que atingem $20-25 \mathrm{~m}$ de altura, entremeadas por espécimes emergentes de até $30 \mathrm{~m}$. As comunidades estabelecidas sobre solos mais profundos apresentam elevado número de indivíduos por hectare e grande variação de espécies, ao contrário das desenvolvidas sobre solos residuais, menos densas. As espécies dominantes inserem-se nas famílias Euphorbiaceae (burra leiteira), Moraceae (morácea chocolate, caxinguba), Burseraceae (breu-manga), Fabaceae (cerejeira) e Mimosaceae (Ingaxixi). Palmeiras são comuns em terrenos úmidos e vales. A submata é densa e obstruída por cipós que raramente envolvem as copas de árvores emergentes.

$\mathrm{Na}$ área 2 (Fig. 1), predomina ainda o ambiente fitogeográfico de floresta estacional semidecidual submontana, mas sem a característica do dossel emergente, desenvolvida sobre argissolo vermelho-amarelo eutrófico. Ocorre ainda, na porção oeste, ambiente de floresta estacional semidecidual de terras baixas, desenvolvida em relevos aplainados sobre argissolo vermelho-amarelo distrófico (IBGE online). Os solos em ambos ambien-

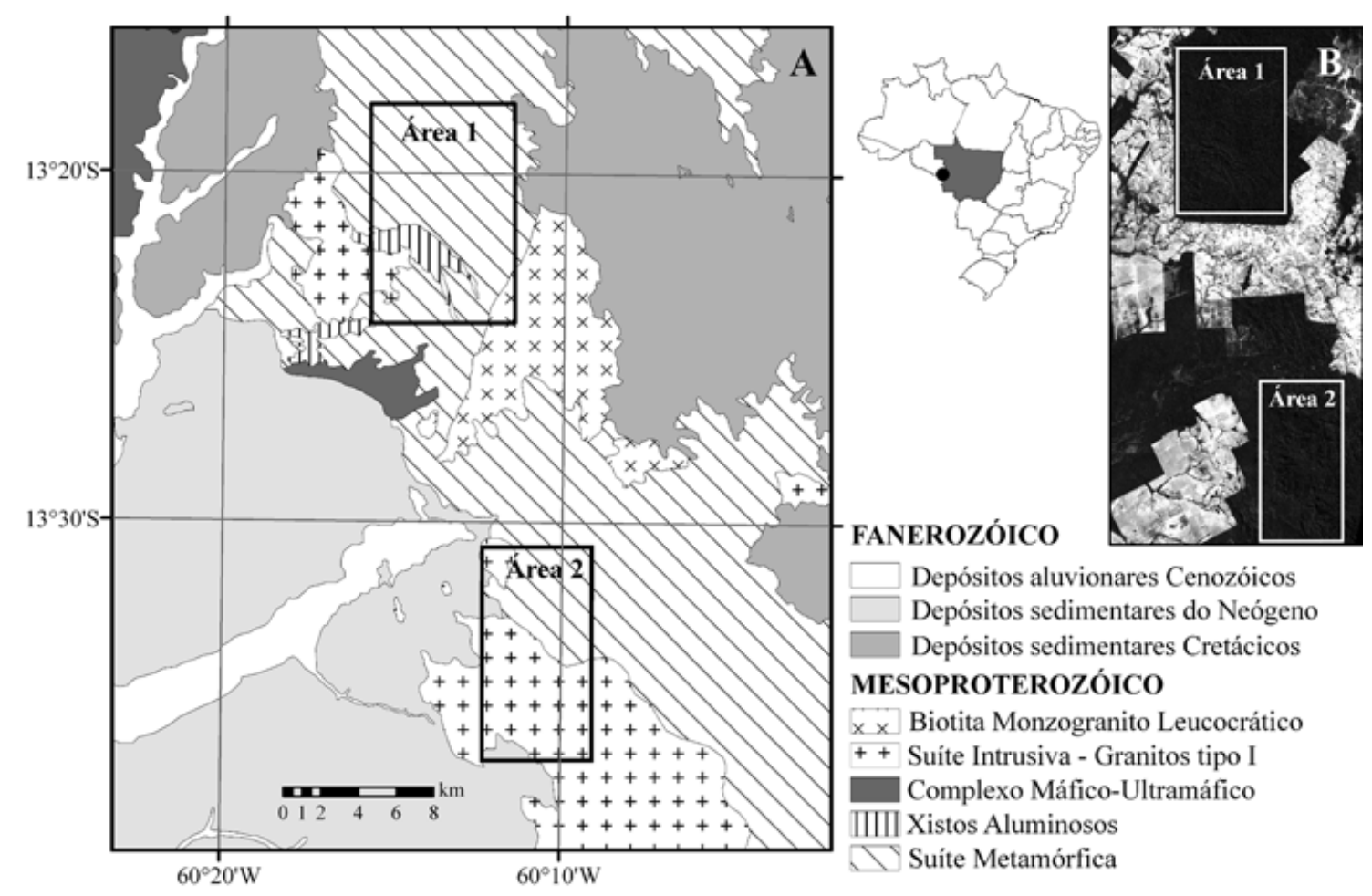

Figura 1 - Extrato do mapa geológico preliminar da Folha Pimenteiras (1:250.000) com localização das áreas de estudo (fonte: Rizzotto 2006) (A). Imagem da banda 2 do sensor ASTER e localização das áreas de estudo (B). 
tes fitogeográficos são descritos como provenientes da decomposição de rochas pré-Cambrianas do Complexo Xingu (Brasil/DNPM 1979). Conforme descrito no projeto RADAMBRASIL (Brasil/DNPM 1979), caracteriza a floresta estacional semidecidual de terras baixas uma composição estrutural e florística heterogênea, representada por uma mistura de árvores relativamente baixas e finas, entremeadas por grupamentos de palmeiras, cipós e bambus. A maioria dos indivíduos apresenta fustes retos e cilíndricos e copas geralmente pequenas e espaçadas, proporcionando penetração de luz nos estratos inferiores. As espécies deciduais distribuem-se intermitentemente pela floresta, ou formam colônias gregárias nos terrenos de lençol freático profundo. A altura média das árvores componentes do dossel emergente varia entre 20 e $25 \mathrm{~m}$, distinguindo-se espécies das famílias Tiliaceae (açoita-cavalo), Apocynaceae (amarelão), Burseraceae (breu-manga) e Fabaceae (cobaíba). A submata é densa e obstruída por cipós. Nos vales e em substratos úmidos ocorrem povoamentos de palmeiras.

Nos extremos sudeste e sudoeste da área ocorre savana florestada sobre solos que têm como substrato depósitos sedimentares do Neógeno.

Num estudo da influência do solo e topografia sobre variações da composição florística num ambiente de floresta estacional semidecidual em Ingaí, MG, Botrel et al. (2002) concluem que, dadas as correlações entre várias espécies com as classes de drenagem e de saturação por bases dos solos analisadas, a disponibilidade de água e de nutrientes minerais são as principais varáveis ambientais determinando a distribuição das espécies na floresta. Estes autores alertam que nem sempre variáveis fundamentais no estudo da distribuição das espécies, tais como condições de luz e água, são facilmente perceptíveis e mensuráveis, além do que, as espécies são sensíveis às variáveis ambientais de uma forma interativa e respondem a elas num ambiente de competição entre as espécies.
MATERIAIS E MÉTODOS DE PROCESSAMEN-

TO Os dados de sensoriamento remoto óptico utilizados neste estudo compreendem uma cena do sensor ASTER (Advanced Spaceborne Thermal Emission and Reflection Radiometer), de identificação: AST_L1B_003_080420 01143459_08132001090542, datada de 4 de agosto de 2001 , com centro nas coordenadas $13,5^{\circ} \mathrm{S}$ e $60,42^{\circ} \mathrm{W}$.

$\mathrm{O}$ pré-processamento da imagem compreendeu:

1- correção do efeito de cross-talk, através do programa CRSTK30 (ERSDAC 2006);

2- ortorretificação da cena, utilizando-se o modelo digital de terreno extraído diretamente das bandas ASTER 3N e ASTER 3B. Este procedimento foi feito anteriormente aos passos subseqüentes dada a necessidade de leitura de parâmetros no arquivo original pelo software utilizado. Dado o caráter das técnicas aplicadas no processamento (descritas a seguir), os resultados obtidos com a aplicação do método na imagem sem ortorretificação indicaram que este procedimento anterior ao processamento propriamente dito não causa alterações significativas nos produtos finais;

3- reamostragem das bandas do infravermelho de ondas curtas (SWIR) para resolução espacial de 15 metros, compatível com a resolução das bandas do visível e infravermelho próximo (VNIR);

4- compensação atmosférica da cena, por modelo de transferência radiativa MODTRAN;

5- recorte para extração de áreas contendo apenas a mata original preservada. Duas áreas foram selecionadas para estudo. A área 1 apresenta maior diversidade de litotipos e contraste composicional entre os mesmos em relação à área 2.

Os parâmetros estatísticos das bandas ASTER submetidas a este pré-processamento estão apresentadas na figura 2 e tabela 1.

A seqüência de processamentos aplicada seguiu o procedimento descrito em Almeida (2005) e envolveu cinco passos:

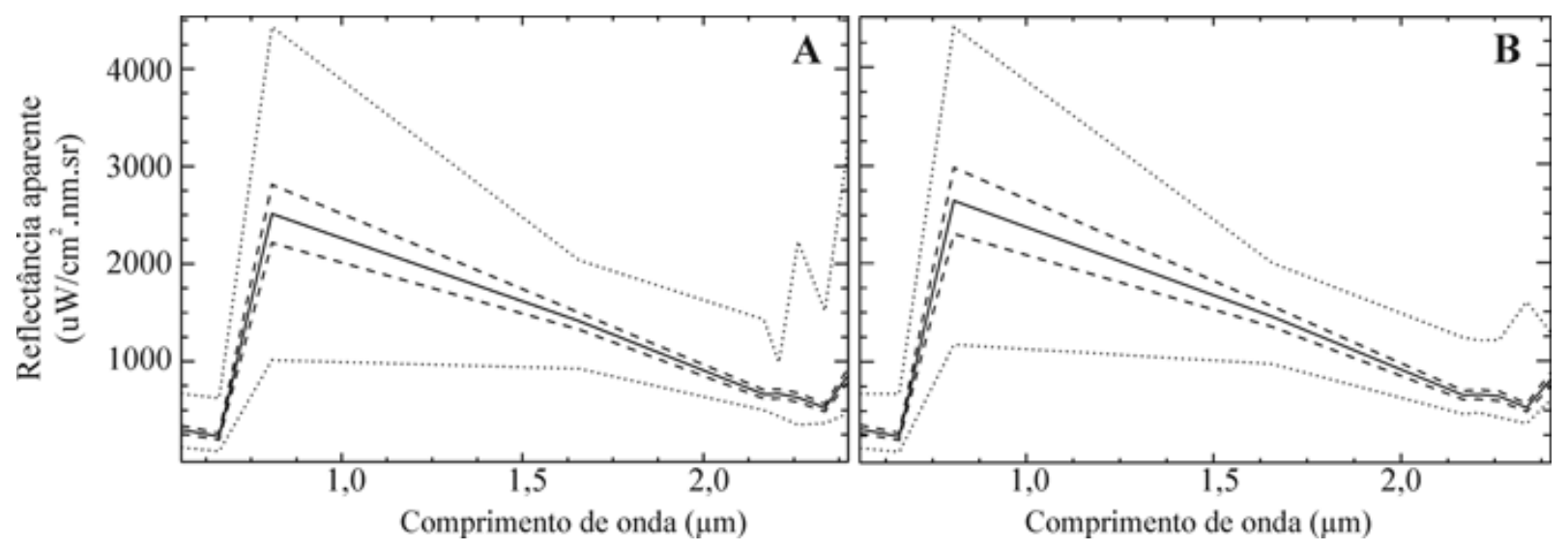

Figura 2 - Curvas de reflectância espectral derivadas dos pixels extraídos da imagem ASTER (bandas 1-9), após compensação atmosférica dos dados, na área 1 (A) e na área 2 (B). O gráfico mostra a variação estatística da reflectância em todos os pixels compreendidos nas áreas de estudo. Linha contínua = média. Linha tracejada = média mais e menos desvio padrão. Linha pontilhada = mínimo e máximo. Os dados numéricos são apresentados na tabela 1. 
Tabela 1 - Dados sobre a variação estatística da reflectância da vegetação na resolução espectral do sensor ASTER e considerando todos os pixels nas duas áreas de estudo.

\begin{tabular}{|c|c|c|c|c|}
\hline área & 1 & 1 & 1 & \\
\hline banda & mínimo & máximo & média & $\begin{array}{l}\text { desvio } \\
\text { padrão }\end{array}$ \\
\hline ASTER 1 & & & & \\
\hline ASTER 2 & & & & \\
\hline ASTER 3 & & & & \\
\hline ASTER 4 & & & & \\
\hline ASTER 5 & & & & \\
\hline ASTER 6 & & & & \\
\hline ASTER 7 & & & & \\
\hline ASTER 8 & & & & \\
\hline ASTER 9 & & & & \\
\hline
\end{tabular}

1- Realce espectral de diferentes compostos foliares por meio de índices espectrais ou razões de bandas. Oito razões de bandas foram preparadas utilizandose no numerador sempre a banda ASTER 3 (NIR: 780$860 \mathrm{~nm}$ ) como comprimento de onda de referência. É nesta região do espectro que a radiação eletromagnética (REM) é fortemente refletida pela vegetação devido à presença de pigmentos foliares transparentes. As demais bandas, no denominador, como comprimentos de onda índice, representam: ASTER 1 e 2 (VIS: $520-690 \mathrm{~nm}$ ), faixa de absorção por pigmentos foliares tais como clorofila, carotenóides e antocianina (Fig. 3A); ASTER 4 a 9 (SWIR: $1600-2430 \mathrm{~nm}$ ), domínio da água na estrutura foliar com máximo de reflectância em $1650 \mathrm{~nm}$ (ASTER 4) e feições de absorção ligadas a compostos bioquímicos tais como amido (ASTER 5, 6 e 7), lignina, proteínas e açúcares (ASTER 8) (Fig. 3B).

2- Aplicação de análise por principais componentes (APC) sobre o conjunto de razões de bandas, objetivando a concentração e hierarquização da informação espectral;

3- Análise das estatísticas produzidas na APC, para seleção dos tripletes que melhor expressam as variações espectrais realçadas nas razões de banda.

4- Aplicação de filtro de convolução do tipo passa-baixa sobre as componentes principais selecionadas no item 3, sendo que no presente estudo foi escolhido um filtro linear de 17 elementos;

5- Introdução de imagem de albedo (primeira componente de APC sobre as bandas originais) através
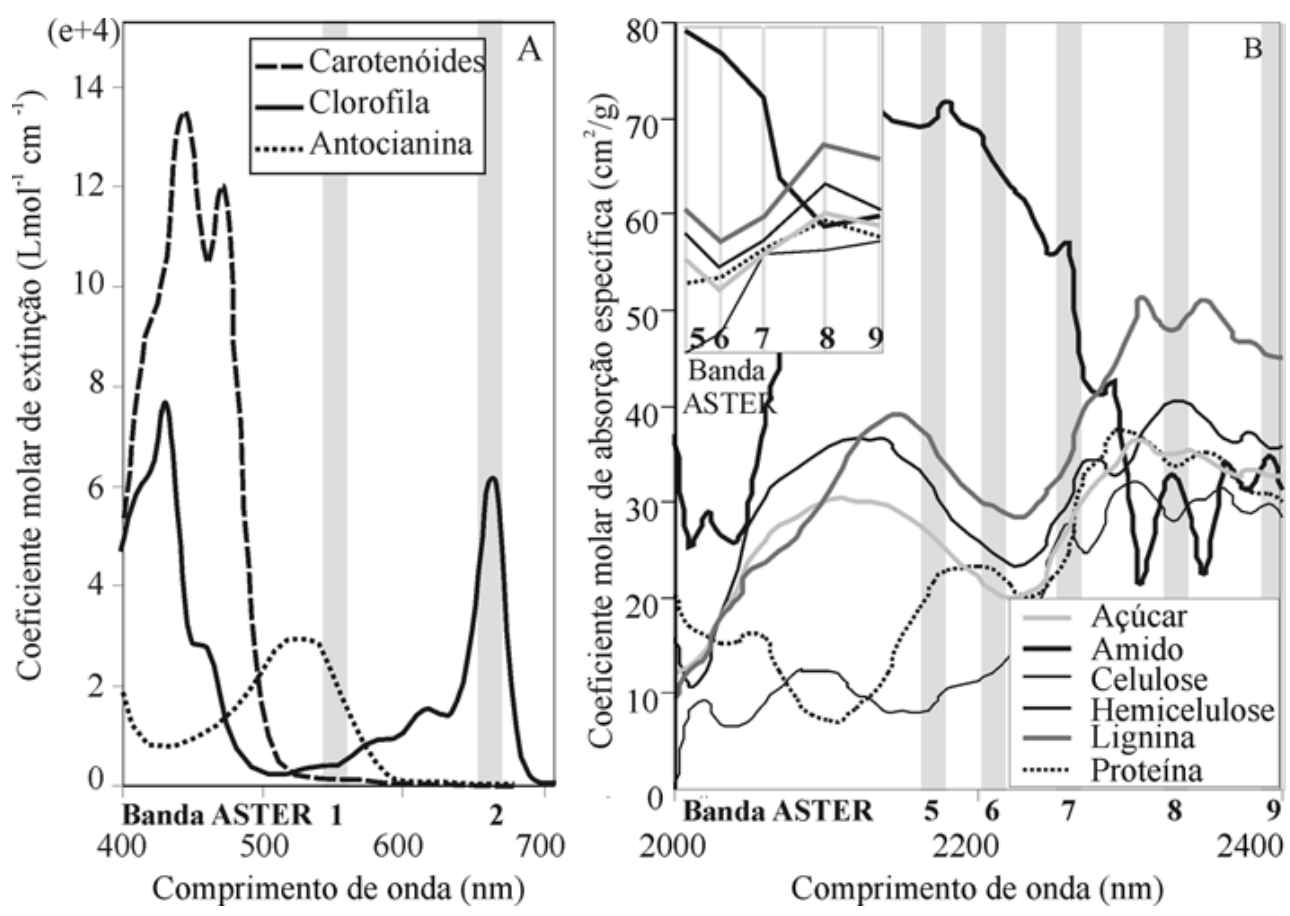

Figura 3 - Espectros de absorção de carotenóides, clorofila e antocianina (A). Espectros de absorção de proteina, celulose, hemicelulose, amido, açúcar e lignina em folhas secas (B). (Baret 1999 in: Almeida 2005). No detalhe da figura 3B, são ilustrados espectros re-amostrados para a resolução espectral do sensor ASTER. 
de fusão, por processamento do tipo IHS, com os tripletes escolhidos para interpretação, estes já submetidos a ampliações adequadas de contraste. Esta imagem de albedo, além de informar da textura do relevo, aspecto essencial na interpretação geológica, informa também, pixel a pixel, do albedo do dossel florestal. Este albedo relaciona-se à estrutura da floresta e à arquitetura do dossel e informa da fisionomia da floresta, aspecto essencial na diferenciação de coberturas vegetais, como apresentado em Almeida (2005) e em Almeida et al. (2007b).

Exemplos de produtos desta seqüência de processamentos estão ilustrados nas figuras 4A, 4B, 5A e 5B.

Numa variação do método descrito acima, no passo 2 foi também aplicada uma análise do tipo MNF (Minimum Noise Fraction). Neste método de determinação da dimensionalidade dos dados, uma transformação por principais componentes, baseada numa matriz de covariância do ruído estimado, precede uma APC final sobre os dados sem ruído (Green et al. 1988). Exemplos de produtos gerados a partir desta técnica estão expostos nas figuras $4 \mathrm{C}$ e $5 \mathrm{C}$.

Os dados aerogeofísicos de gamaespectrometria utilizados foram coletados no Projeto Aerogeofísico Sudeste de Rondônia (RO - MT) (metadados em CPRM 2007), com linhas de vôo espaçadas de $500 \mathrm{~m}$. A partir desses dados foram gerados grids com malha quadrada de $125 \mathrm{~m}$, através do método da mínima curvatura, os quais foram reamostrados para $20 \mathrm{~m}$ de resolução. Para interpretação qualitativa da aerogamaespectrometria estes grids foram transformados em imagens no formato geotiff em três canais de cor (RGB) de forma a refletir a escala original de cores que associa valores radiométricos baixos a altos a cores azul, ciano, verde, amarelo, laranja, vermelho e magenta. A combinação das imagens gamaespectrométricas com a informação textural da superfície, realçada na imagem Principal Componente 1 (PC1), obtida através da APC sobre o conjunto de bandas ASTER originais, facilita a interpretação dos padrões aerogeofísicos relacionados aos litotipos com a possibilidade de se correlacionar os padrões radiométricos observados com as feições topográficas e texturais do terreno. Esta combinação foi feita através de técnica de fusão do tipo IHS. Exemplos destas imagens podem ser observados nas figuras 4D a 4F, 5D a 5F.

RESULTADOS Comportamento espectral da vegetação Espectros da vegetação coletados das imagens submetidas à compensação atmosférica (área 1) conforme variações tonais na composição B3-B1-B2 em R-G-B (Fig. 6A) mostram, no geral, dois grupos de comportamento distinto: curvas com ou sem leve feição de reflexão na banda 4. No primeiro caso, nota-se que valores de reflectância menos elevados na banda 3 geralmente são acompanhados por valores também menos elevados na banda 4 , e relativamente muito menos elevados na banda 5 , resultando em feição espectral característica. Já no segundo caso, valores mais elevados na banda 3 são acompanhados de valores mais elevados na banda 4, mas relativamente mais elevados na banda 5, de maneira a não configurar a infle- xão na curva espectral. Nestes pixels selecionados, as demais bandas do SWIR, exceto por uma clara feição de absorção na banda 8 , não mostraram padrões homogêneos de comportamento. Os mesmos, coletados na imagem Razão de Bandas (Fig. 6B), mostram realce de feições relativas a cada porção do espectro, mas no geral pouca distinção entre as curvas, ao contrário dos mesmos pixels coletados na imagem das Principais Componentes das razões de bandas, onde a distinção entre as curvas e, conseqüentemente, entre os pixels é bem mais evidente (Fig. 6C). Por outro lado, pixels coletados conforme tons de cor distintos na imagem Principais Componentes apresentam curvas bastante diferentes entre si (Fig. 6D), ao contrário dos mesmos pixels na imagem original (Fig. 6E) e na imagem Razão de Bandas (Fig. 6F), justificando assim o método de processamento empregado no realce das variações no comportamento espectral da vegetação.

Resultados estatísticos da Análise de Principais Componentes e Minimum Noise Fraction A análise por principais componentes, com o objetivo de concentração e hierarquização da informação espectral, mostrou resultados semelhantes em ambas as áreas (autovetores na tabela 2):

- a PC1, que concentra mais de $70 \%$ da variação dos dados (Tab. 3), é dominada pelas razões que envolvem as bandas do visível, principalmente a razão 3/2, onde são observadas as maiores variâncias (Tab. 4);

- a PC2, com aproximadamente $15 \%$ da informação (tabela 3), concentra, de forma negativa, a informação das razões entre a banda ASTER 3 e as bandas do SWIR, exceto a banda 4 , além de alguma contribuição positiva das razões da banda 3 com as bandas do visível;

- a PC3, que representa aproximadamente 5\% da informação, é novamente dominada pelas razões que envolvem as bandas do visível, principalmente a razão $3 / 1$, mas com sinais trocados;

- nas PCs de 4 a 7 a maioria da informação provinda das razões $3 / 1,3 / 5,3 / 6,3 / 7,3 / 8$ e 3/9 é discriminada em componentes diferentes (em itálico na tabela 2), mas feições de ruído predominam fortemente.

- a PC8, que explica menos de $1 \%$ da variação da informação (Tab. 3), concentra quase que exclusivamente a informação da razão 3/4 e apresenta coerência espacial satisfatória. Este fato parece estar associado à baixa variância desta razão e à muito baixa covariância entre essa e as demais razões (Tab. 4).

Tripletes RGB que envolvem as bandas PC1, PC2, PC3 e PC8 foram escolhidos para interpretação já que este conjunto de componentes tem a propriedade de hierarquizar a informação relativa a cada porção do espectro eletromagnético e ao essencial dos compostos foliares com resposta espectral. As figuras 4A, 4B, 5A e $5 \mathrm{~B}$ mostram resultados de tripletes que envolvem estas componentes, já submetidos a um filtro tipo passabaixa 17X17, e com a introdução da imagem de albedo para as áreas 1 e 2 , respectivamente.

O processamento através da análise Minimum Noise Fraction gerou conjuntos MNF com os autoveto- 

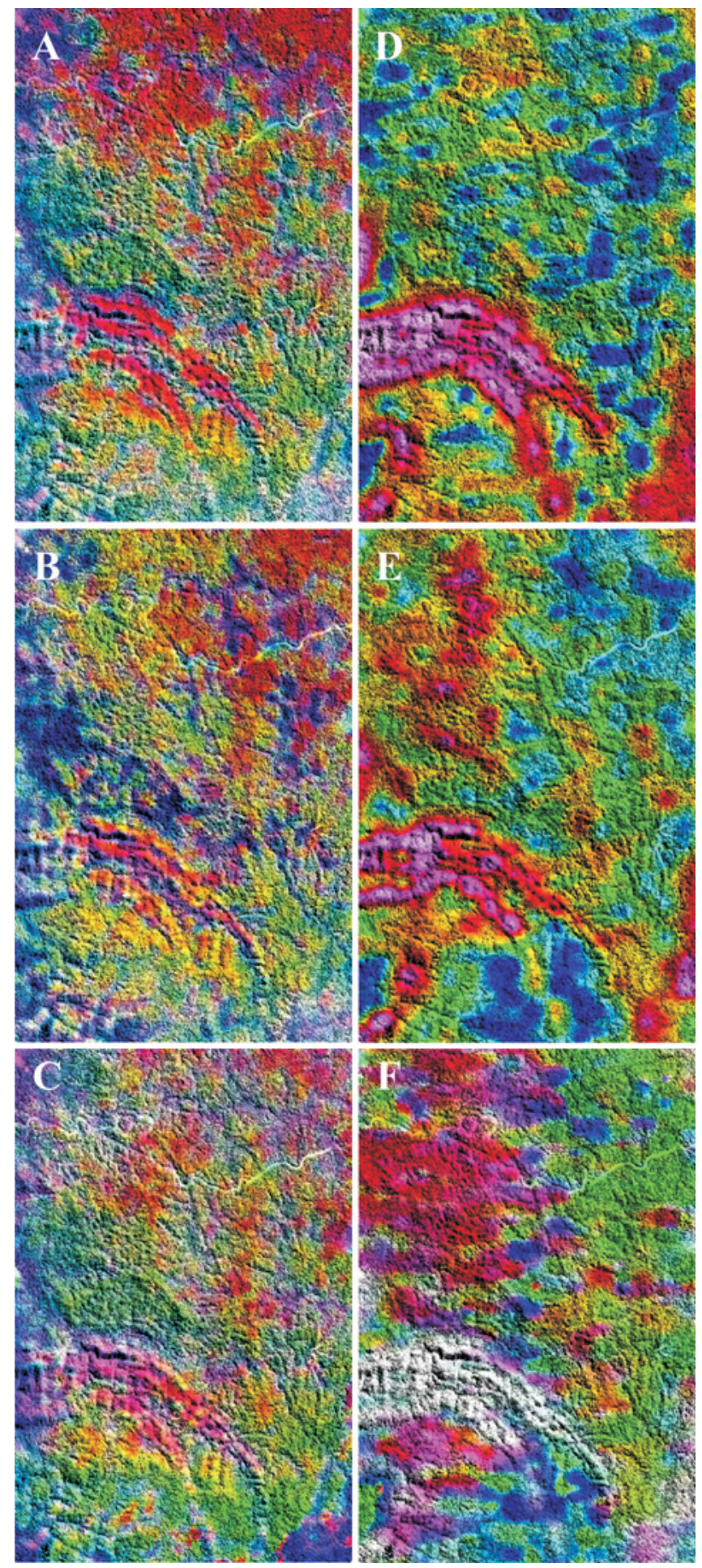

Figura 4 - Área 1. Produtos derivados da APC e MNF de razões de bandas. As componentes foram: (i) filtradas por um filtro passa-baixa e (ii) submetidas a uma transformação IHS para introdução da PC1 das bandas ASTER originais no canal de intensidade. $(A)$ e (B): razões b3/demais bandas, (C): razões b3/b2, b3/b4, b3/b5, b3/ b6, b3/b8. PC1-PC8-PC2 em R-G-B (A). PC1-PC3-PC2 em $R-G-B(B)$. (-MNF1)-(-MNF5)-MNF4 em $R-G-B(C)$. $D, E, F$ : imagens aerogeofisicas. A PC1 das bandas ASTER originais foi alocada ao canal de intensidade para realce textural das imagens. Canal do eTh $(D)$, canal do $K(E)$, distribuição ternária (K-U-Th em $R-G-B)(F)$.
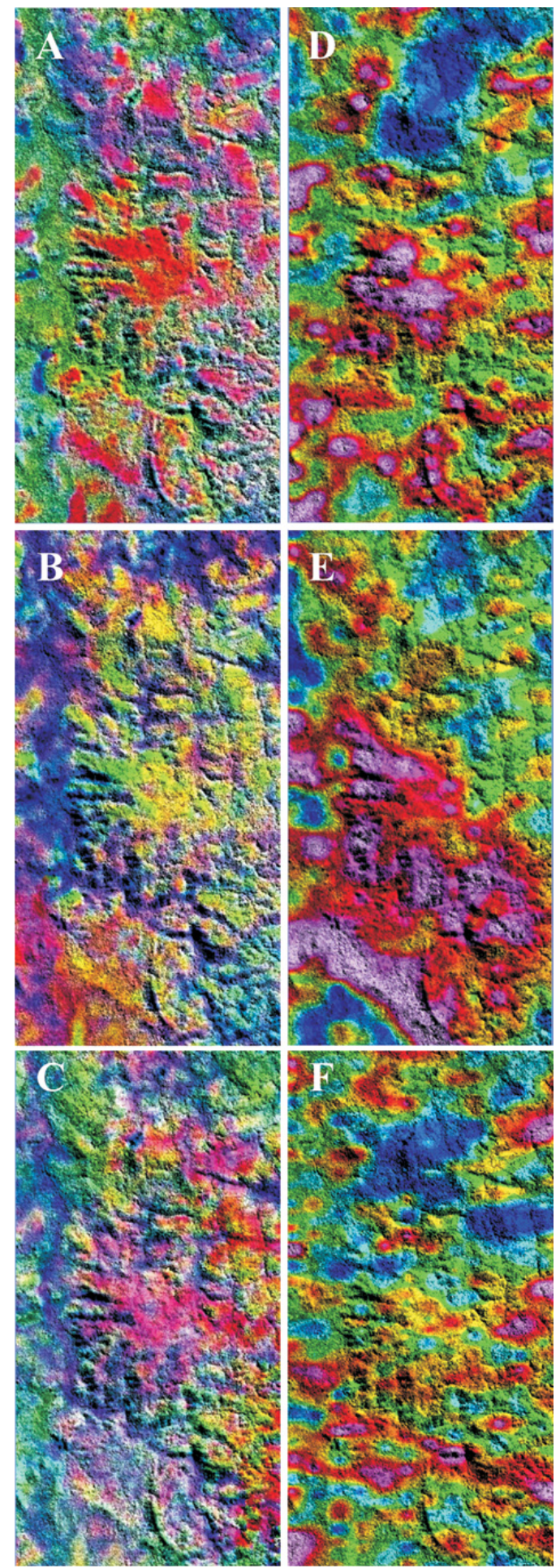

Figura 5 - Área 2. Produtos derivados da APC e MNF de razões de bandas. As componentes foram: (i) filtradas por um filtro passa-baixa e (ii) submetidas a uma transformação IHS para introdução da PCl das bandas ASTER originais no canal de intensidade. (A) $e$ (B): razões b3/demais bandas, $(C)$ : razões b3/b2, b3/ $b 4, b 3 / b 5, b 3 / b 6, b 3 / b 8$. PC1-PC2-PC8 em R-G-B (A), $P C 3-P C 1-P C 2$ em R-G-B (B), MNF1-MNF5-MNF3 em $R-G-B(C)$. (D), (E) e (F): imagens aerogeofísicas. A PC1 das bandas ASTER originais foi alocada ao canal de intensidade para realce textural das imagens. Canal do eTh (D), canal do $K(E)$, canal do eU $(F)$. 

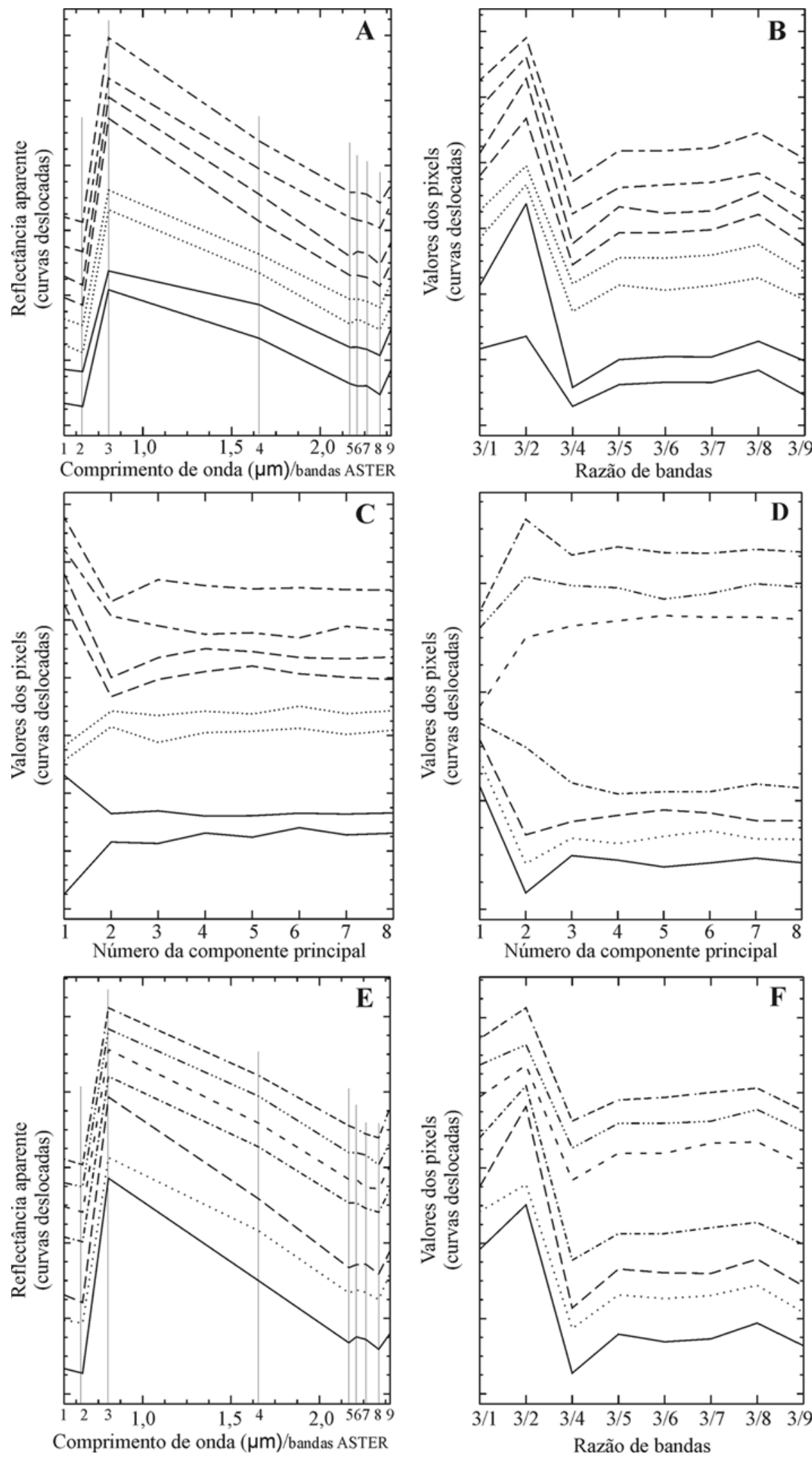

Figura 6 - Área 1. Em (A)-(C), assinaturas de pixels representativos da vegetação extraídas conforme variações tonais na composição b3-b1-b2 em R-G-B. Os valores foram extraídos de imagens convertidas para reflectância (com compensação atmosférica) (A), de imagens de razões de bandas (3/1; 3/2; 3/4; 3/5; 3/6; 3/7; 3/8; 3/9) (B), e de imagens de Principais Componentes das razões de bandas $(C)$. Em (D)-(F), valores extraídos de pixels contendo vegetação e considerando variações tonais nas imagens de Principais Componentes. Os valores foram derivados de pixels nos conjuntos das Principais Componentes (D), das bandas convertidas para reflectância (E) e das razões de bandas (F). 
Tabela 2 - Matriz de autovetores da APC sobre o conjunto de razões de bandas processadas. Em negrito as contribuições dominantes nas PCs selecionadas para tripletes RGB apresentados nas figuras 4A, 4B, 5A e 5B. Em itálico as maiores contribuições de cada uma das razões de bandas.

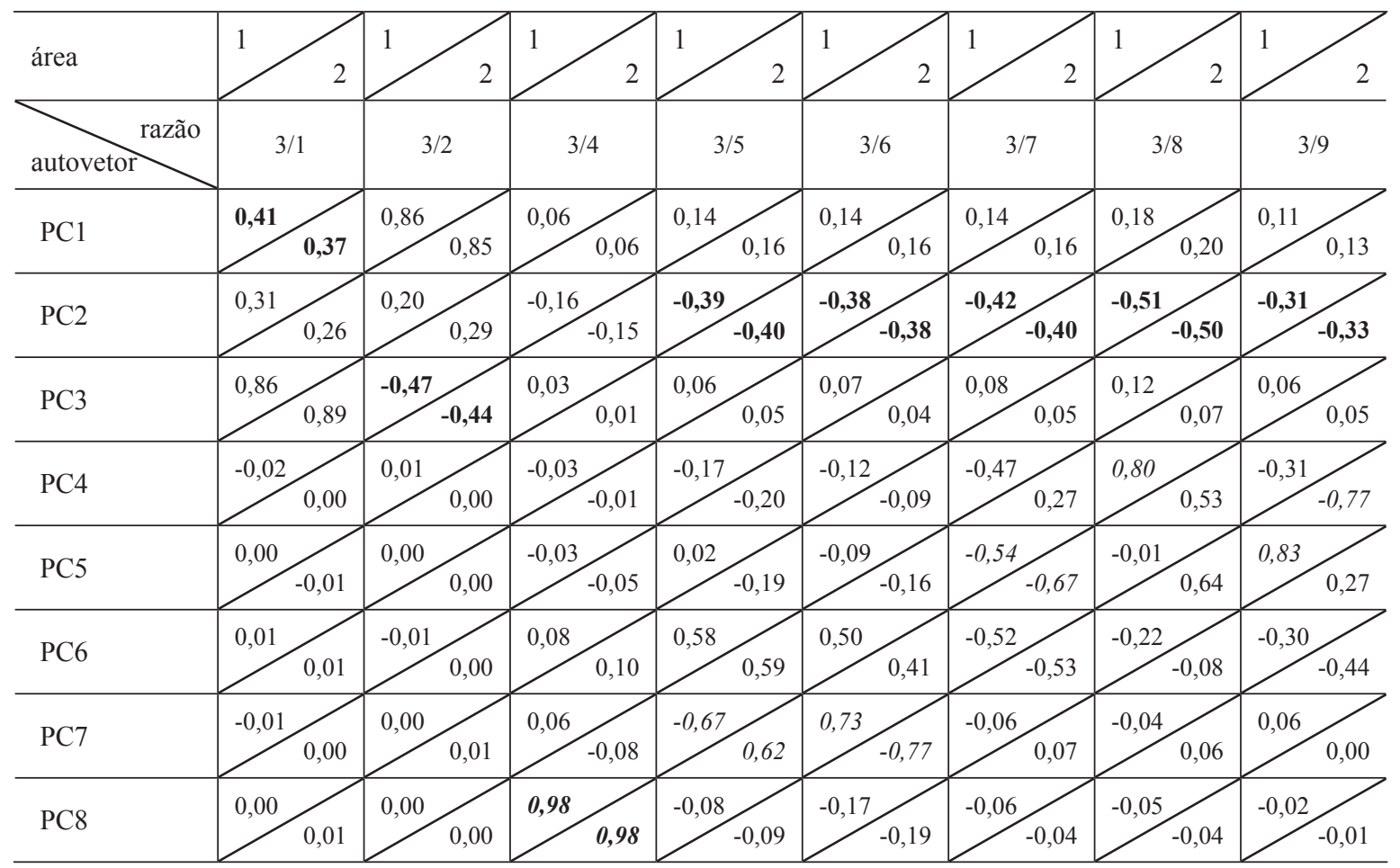

res apresentados na tabela 5. Dentre estas componentes feições de ruído sistemático são observadas nas componentes MNF2, MNF3, MNF4 e MNF6 no caso da área 1, e MNF2, MNF3, MNF5 e MNF6 no caso da área 2, apesar de todas apresentarem autovalores superiores a 1 , isto é, todas contém dados. Nota-se que neste procedimento, em ambas as áreas, a informação das razões da banda $3 \mathrm{com}$ as bandas do visível estão concentradas na penúltima componente, que representa $10 \%$ do total da informação e apresenta relativa coerência espacial. Estas bandas também apresentam contribuição importante na primeira componente ( $23 \%$ da informação), mas com sinais trocados, assim como em quase todas as outras componentes. Esta inversão de sinais pode estar relacionada à feição espectral característica de pigmentos não clorofilianos na banda $1 \mathrm{e}$ de clorofila na banda 2 (Fig. 3). A informação da razão 3/4 é essencialmente concentrada na última componente, que representa aproximadamente $5 \%$ do total da informação, com alguma coerência espacial preservada, e ausência de feição de ruído sistemático. Ao contrário da APC, nenhuma componente foi capaz de concentrar homogeneamente contribuições significativas do conjunto de razões da banda 3 com as demais bandas do SWIR, mas sim estas razões foram discriminadas em diferentes componentes.

Em vista da capacidade do processamento MNF de distribuir em componentes diferentes e espacialmente coerentes as diversas razões relativas às várias faixas do espectro eletromagnético, selecionou-se, dentre
Tabela 3 - Autovalores (em porcentagem) das componentes principais.

\begin{tabular}{l|c|c}
\hline & $\begin{array}{c}\text { autovalores (\%) - } \\
\text { área 1 }\end{array}$ & $\begin{array}{c}\text { autovalores (\%) - } \\
\text { área 2 }\end{array}$ \\
\hline PC1 & 74,396 & 78,120 \\
\hline PC2 & 16,797 & 14,248 \\
\hline PC3 & 5,117 & 4,324 \\
\hline PC4 & 1,311 & 1,140 \\
\hline PC5 & 1,055 & 0,972 \\
\hline PC6 & 0,714 & 0,738 \\
\hline PC7 & 0,535 & 0,398 \\
\hline PC8 & 0,074 & 0,062 \\
\hline
\end{tabular}

as razões, as que poderiam ser mais representativas dos compostos foliares, com base nas curvas características dos espectros de absorção destes compostos apresentadas nos gráficos das figuras $3 \mathrm{~A}$ e $3 \mathrm{~B}$. São elas $3 / 2$ (clorofila), 3/5 e 3/6 (amido) e 3/8 (lignina). A razão 3/4 foi incluída por ser representativa da água na estrutura foliar.

As análises Minimum Noise Fraction deste conjunto apresentam os autovetores mostrados na tabela 6 . Feições de ruído sistemático aparecem na componente MNF3 e menos fortemente na MNF2 no caso da área 1, e na MNF2 e menos fortemente na MNF4 no caso da 
Tabela 4 - Matriz de covariância entre razões de bandas processadas.

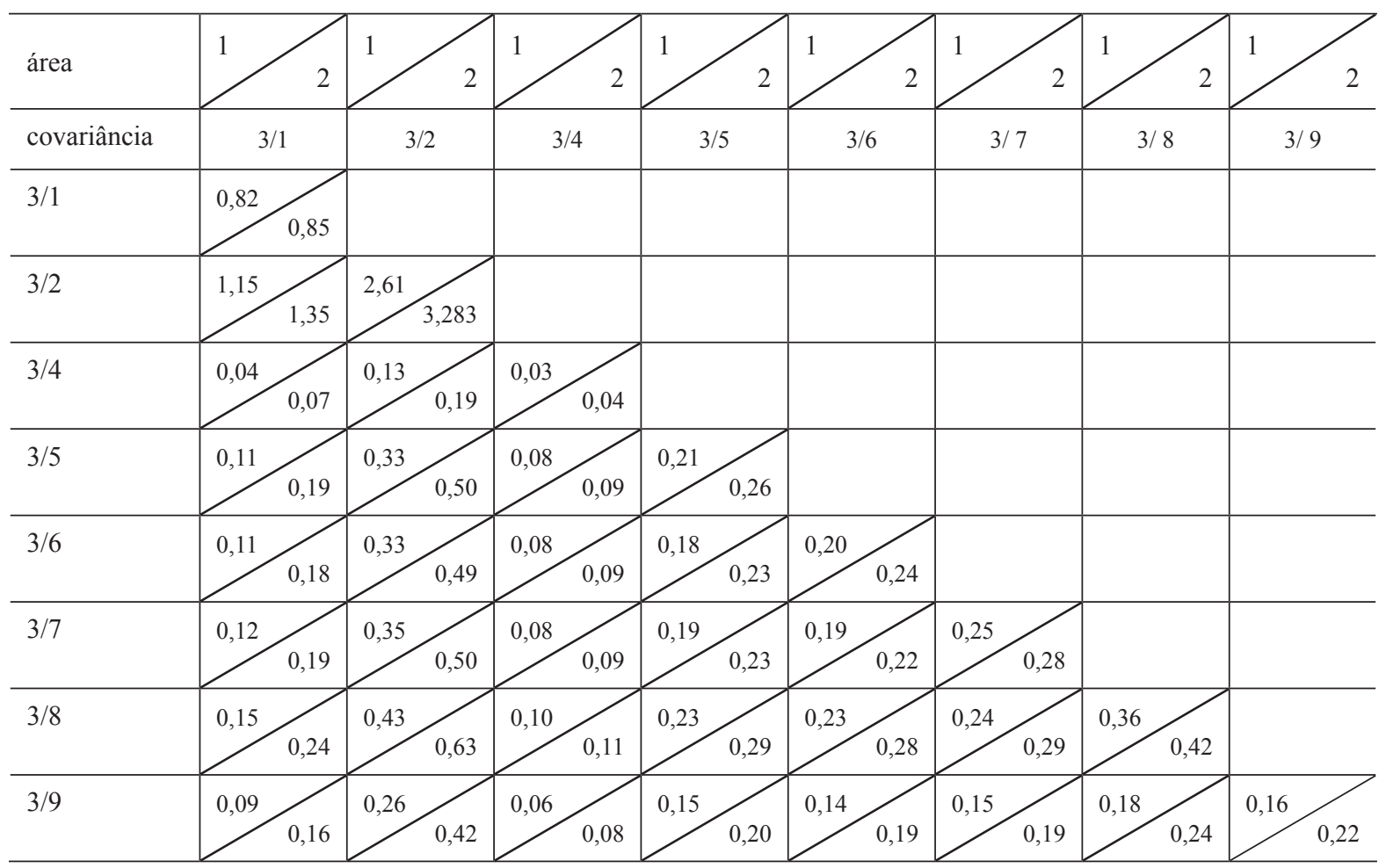

Tabela 5 - Matriz de autovetores da MNF sobre o conjunto de razões de bandas processadas. Em itálico as maiores contribuições de cada uma das razões de bandas.

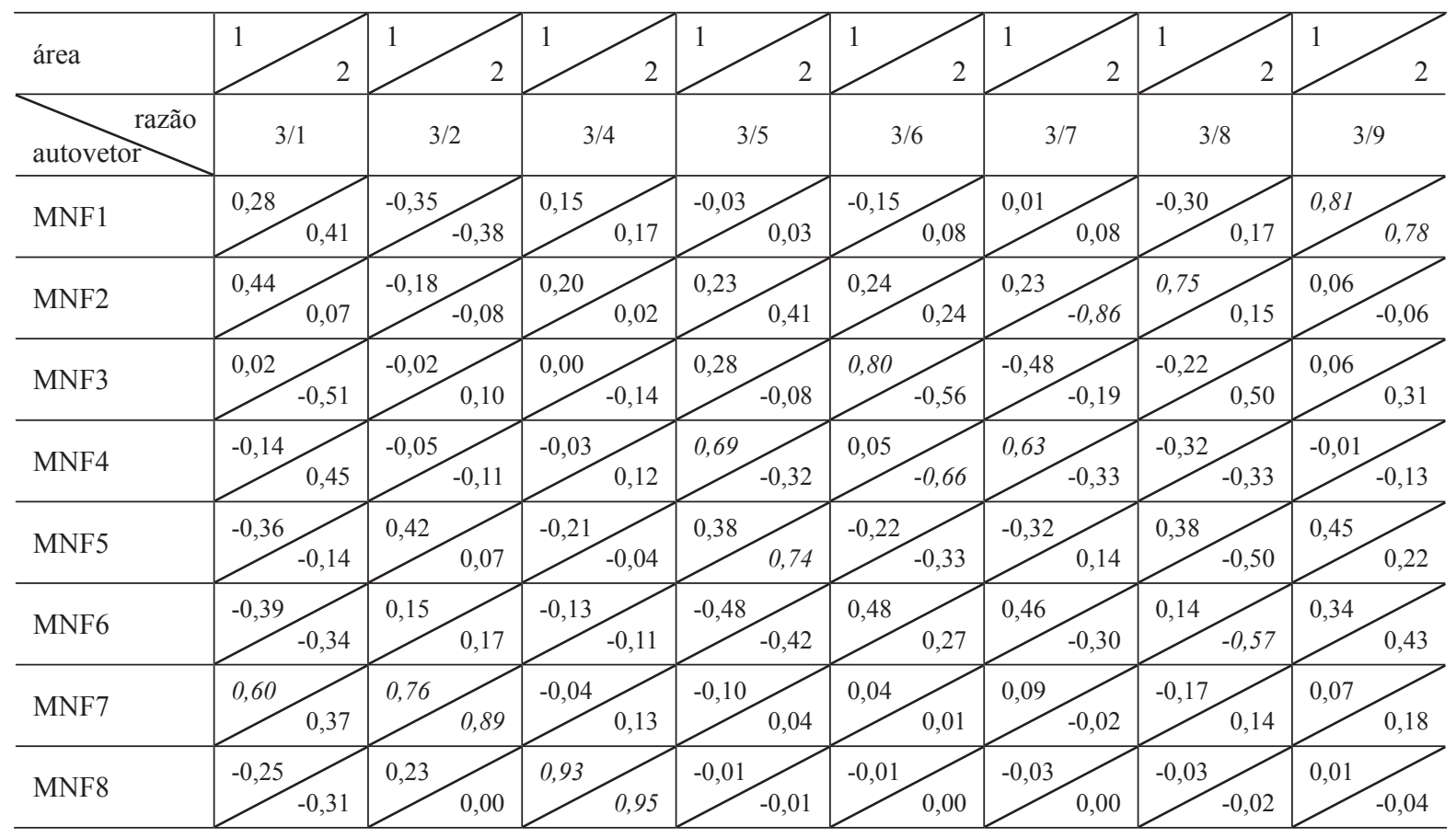

área 2. Os melhores tripletes produzidos por estas componentes envolvem sempre a MNF1 e a MNF5, dominadas pela informação das razões $3 / 8,3 / 4$ e 3/2. A complementação do triplete com qualquer das outras componentes, contando com contribuição significativa seja da banda $3 / 5$ ou da $3 / 6$, não altera significativamente $o$ produto final. Exemplos destes tripletes, já submetidos à filtragem de passa-baixa e introdução da imagem de albedo, estão apresentados nas figuras $4 \mathrm{C}$ e $5 \mathrm{C}$.

DISCUSSÃO Tanto os produtos gerados pela manipulação das imagens do sensor ASTER quanto os aerogeofísicos apontam para uma maior complexidade litológica da área do que a apresentada no mapa geológico 
preliminar, elaborado sem o uso destas ferramentas (Fig. $1)$.

Um ensaio de interpretação dos dados, com base na área 1 (Fig. 7), foi realizado em ambiente GIS de forma que todas as imagens pudessem ser avaliadas em conjunto. Para maior coerência dos contatos traçados, incorporou-se ainda a digitalização de feições lineares do terreno, extraídas analogicamente da primeira componente principal (PC1) do conjunto de bandas original do VNIR e SWIR.

Nota-se nas figuras 4 e 5 que existem várias coincidências entre as imagens ASTER processadas e as gamaespectrométricas. Como feição mais marcante na área 1 a dobra na porção centro-sudoeste fica evidente em todas as imagens geradas, correspondendo a alto radiométrico em todos os temas geofísicos, marcados por tons magenta nos canais do $e$ Th e K (Figs. 4D e 4E), e tons brancos na distribuição ternária (Fig. 4F). De acordo com dados de campo na extensão oeste desta estrutura e em lente de mesma assinatura radiométrica a noroeste, com controle de campo, seu conteúdo litológico deve corresponder a xistos aluminosos. Os produtos do processamento das imagens ASTER sugerem que estas lentes têm espessuras mais restritas do que poderia ser interpretado pela geofísica, e ocorrem como intercalações no conjunto de rochas metamórficas predominantes na área. Wilford et al. (1997) descrevem assinaturas relativamente altas nos canais $\mathrm{K}, e \mathrm{Th}$ e $e \mathrm{U}$ em regolitos argilosos derivados de xistos e filitos no oeste da Austrália. O elemento $\mathrm{K}$ estaria associado a minerais de argila potássicos e micas enquanto Th e U ocorreriam associados a minerais de argila, óxidos de Fe ou Ti e fragmentos líticos. Não se pode descartar a presença de anatexia nestas rochas, que já se encontram na zona da sillimanita, o que poderia explicar a sustentação do relevo por presença de mobilizados graníticos e ainda um comportamento radiométrico compatível com rochas granitóides nos dados aerogeofísicos. Por outro lado, o relevo mais acentuado pode indicar rochas mais próximas à superfície, o que elevaria, relativamente, os valores radiométricos, apesar da correção topográfica, aplicada aos dados brutos.

A sul desta feição, a variação tonal nas imagens ASTER processadas e o relevo elevado, associados a assinatura alta no canal $\mathrm{K}$ e intermediária nos canais Th e U, sugerem a presença de corpo granítico, num comportamento semelhante aos das fases mais tardias na evolução magmática (Dickson \& Scott 1997).

A unidade mapeada como suíte metamórfica, associada a xistos e paragnaisses, tem assinaturas moderadas e heterogêneas entre os temas geofísicos na porção centro norte da área. Entretanto, tanto nas imagens ASTER, como nas gamaespectrométricas, nota-se que subdivisões podem ser esboçadas organizando-se numa ampla dobra com traço axial de orientação NW (Fig. 7).

No extremo sudoeste, um corpo de metamáfica (reconhecido através de dados de campo adjacentes) fica bem delimitado nas imagens geofísicas, contornado por provável xisto aluminoso.

No extremo sudeste, os dados geofísicos dos ca-
Tabela 6 - Matriz de autovetores da MNF sobre o conjunto das razões 3/2, 3/4, 3/5, 3/6, 3/8. Em negrito as razões dominantes nas MNFs selecionadas para apresentação nas figuras 4 C e 5C. Em itálico as maiores contribuições de cada uma das razões de bandas.

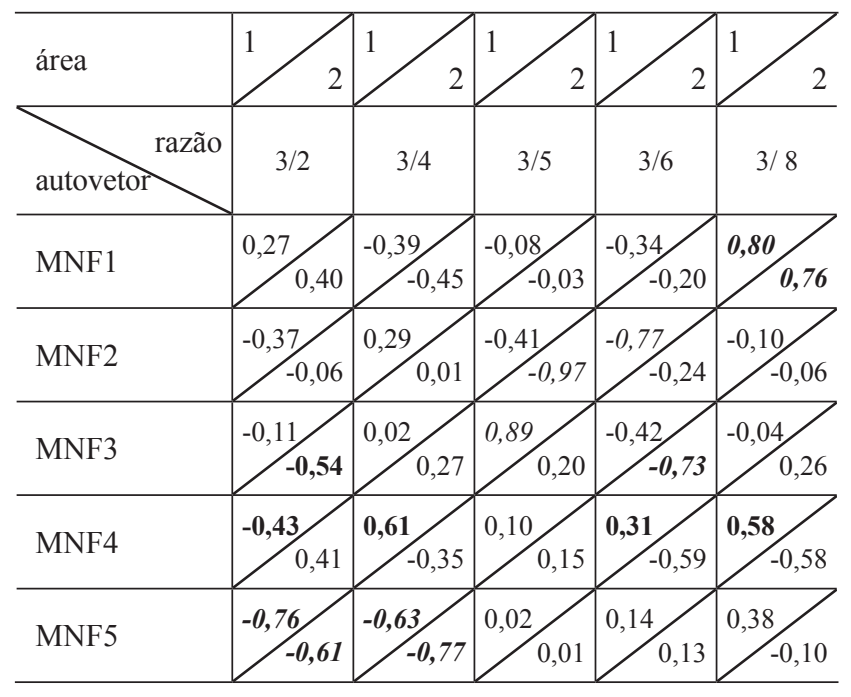

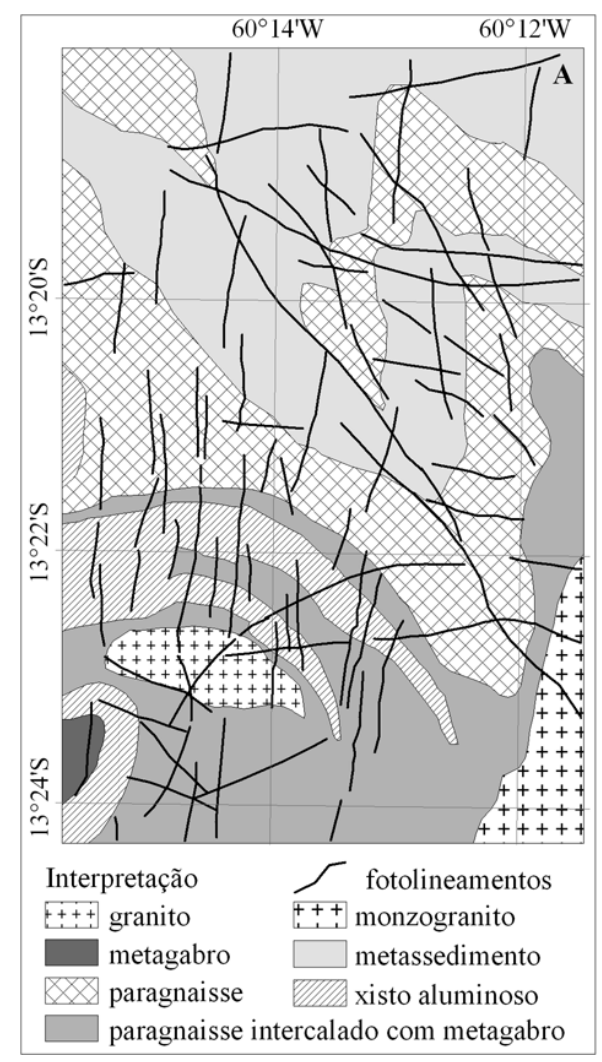

Figura 7 - Interpretação litológica da área 1 baseada nas imagens ASTER processadas, dados aerogeofisicos de gamaespectrometria e dados de campo.

nais do K e $e$ Th e a distribuição ternária KUTh (Figs. 4D, 4E e 4F) indicam, com assinatura radiométrica elevada, a presença do biotita monzogranito mapeado, também evidente nas composições coloridas das figuras 4A a 4C. 
Vale ressaltar que nas bordas oeste e sul da área 1 , próximo à região desmatada, ocorre alteração do sinal espectral que pode ser devido a efeitos residuais do cross-talk (ERSDAC 2006), que afeta principalmente feições separadas por variação brusca de sinal.

$\mathrm{Na}$ comparação da distribuição das feições mapeadas pelas variações tonais nos produtos gerados com o modelo numérico do terreno extraído diretamente dos dados ASTER (Fig. 8A), nota-se algumas coincidências, mas, aparentemente, mais relacionadas às variações na insolação do que às altitudes (Fig. 8C). Assim, nas áreas onde o relevo sombreado mostra incidência solar mais intensa, numa simulação da iluminação natural do sol no horário de passagem do satélite (aproxi-
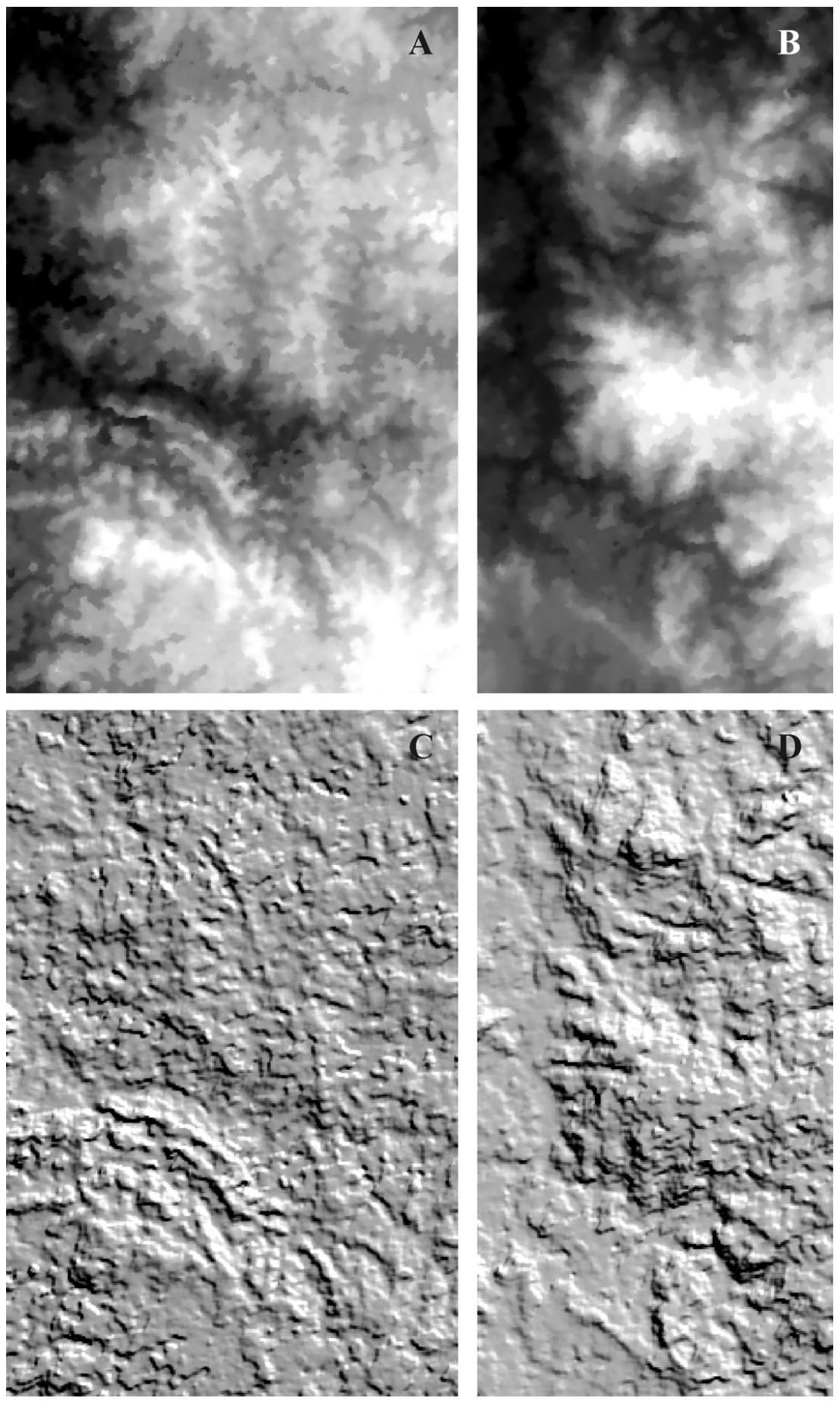

Figura 8 - Modelo Numérico de Terreno extraído automaticamente do par estereoscópico das bandas ASTER $3 N$ e $3 B$, altitudes crescentes de preto para branco. Área 1, altitudes entre 265 e $455 \mathrm{~m}(\mathrm{~A})$; área 2 altitudes entre 245 e $525 \mathrm{~m}$ (B). Equivalentes sombreados com iluminação artificial orientada em $52^{\circ}$ de inclinação e $37^{\circ}$ de azimute, área 1 (C) e área $2(D)$. 
madamente 14h 35m GMT) (Fig. 8C), nota-se que os valores de reflectância na região do verde (banda 1), nas bandas 4, 6, 7 e 8 do infravermelho de ondas curtas e, principalmente, no infravermelho próximo (banda 3) são mais elevados. Se por um lado as variações topográficas refletem diferenças reológicas nas rochas do substrato e suas interações com os processos erosivos, estas variações também são refletidas no estabelecimento da florística, arquitetura do dossel da floresta, no desenvolvimento foliar e na fixação de compostos bioquímicos. Assim todo este conjunto representa um sistema, onde os elementos e processos são fortemente correlacionados, e suas assinaturas se complementam.

No caso da área 2 (Fig. 5), os dados ASTER e aerogeofísicos sugerem contorno e extensão diferente do corpo granítico mapeado, além de indicar a presença de fácies graníticas distintas no seu interior, evidenciadas pela variação tonal nas imagens ópticas e nas assinaturas radiométricas. As últimas sugerem composições mais ácidas ou alcalinas na região central. De fato, afloramentos descritos no mesmo corpo, mais a sul da área de estudo, mostram variações de granulação e composição desde biotita granito até muscovita granito passando por granito a duas micas.

Nesta área, que apresenta desnível topográfico mais acentuado, próximo a $300 \mathrm{~m}$ (cf. modelo numérico de terreno e relevo sombreado nas figuras $8 \mathrm{~B}$ e $8 \mathrm{D}$ ), nota-se uma maior influência do relevo nos dados ópticos. Nesses dados variações tonais também estão em parte associadas às distintas unidades fitogeográficas, com menos variação na região oeste, onde ocorre floresta estacional semidecidual de terras baixas desenvolvida sobre relevo mais aplainado. $\mathrm{O}$ mesmo não ocorre nas imagens gamaespectrométricas corroborando as conclusões de Martelet et al. (2006) que indicam preservação das variações de sinal relacionadas à geologia em detrimento da cobertura vegetal nas áreas de floresta densa. Neste caso os dados gamaespectrométricos, especialmente o canal do potássio (Fig. 5E) assinalam melhor o principal contraste litológico nesta área, o entre a cobertura sedimentar do Neógeno e o corpo granítico predominante. Por outro lado o vale que se estende pela porção oeste com orientação norte-noroeste/sul-sudeste e se inflexiona para sudeste, fica bem demarcado nas imagens ópticas mostrando uma vegetação distinta, desenvolvida sob condições de maior disponibilidade de água, possivelmente sobre depósito aluvionar mais recente, de pequena dimensão, pouco provavelmente identificável na escala de investigação aerogeofísica.

CONCLUSÃO Através da técnica empregada de realce do comportamento espectral da vegetação e de suas variações, estabelecidas no desenvolvimento deste trabalho, diversas imagens foram geradas, representando interações de diferentes porções do espectro eletromagnético concentradas e hierarquizadas através de processos distintos (análise de principais componentes e minimum noise fraction). Se por um lado há redundâncias na informação nelas expressa, por outro, algumas feições particulares, reconhecidas também nas outras fontes de informação (aerogeofísica e dados de campo), mostram a validade destes processamentos na produção de uma série de imagens que se complementam na interpretação. Dada a série de fatores que influenciam o comportamento espectral da vegetação, tais como o solo, topografia do terreno, insolação, disponibilidade de água e o próprio substrato rochoso, nota-se que, da mesma forma como ocorre com as imagens aerogeofísicas, litotipos distintos podem apresentar assinaturas semelhantes, e nem sempre assinaturas semelhantes representam o mesmo litotipo. Assim, acredita-se que a interpretação adequada destas imagens deve ser baseada em contrastes tonais, associando-se sempre os dados texturais e topográficos e observações de campo.

A significativa coerência entre os resultados observados nas imagens geradas por sensores que operam em comprimentos de onda tão distantes, com peculiaridades que só vêm incorporar novos parâmetros à interpretação, indica que a geobotânica por sensoriamento remoto tem alto potencial de aplicação em áreas de floresta tropical, tanto isoladamente como suplementando dados aerogamaespectrométricos.

Agradecimentos Nossos sinceros agradecimentos aos geólogos da Residência de Porto Velho da CPRM, João Marcelo Rodrigues de Castro e Marcos Luiz do Espírito Santo Quadros, pela preparação dos arquivos digitais do mapa geológico da Folha Pimenteiras do oeste 1:250.000 e à Divisão de Geofísica da CPRM, na pessoa do Dr. Luiz Marcelo Fontoura Mourão, pela cessão "pré-lançamento" dos dados aerogeofísicos das áreas de estudo.

\section{Referências}

Agricola G. 1556. De Re Metálica. Froben, Basileae. Translated from Latin by Hoover H.C. \& Hoover L.H. 1912. New York, Dover Publications, Inc., 1986. 640 p.

Almeida T.I.R. 2005. Geobotânica por sensoriamento remoto em florestas tropicais e a abordagem sistêmica: uma ferramenta auxiliar no mapeamento geológico regional e na prospecção mineral. Tese de Livre Docência, Instituto de Geociências, Universidade de São Paulo, 158p.

Almeida T.I.R. \& Souza Filho C.R. 2004. Principal component analysis applied to feature-oriented band ratios of hyper- spectral data: a tool for vegetation studies. International Journal of Remote Sensing, 25:5005-5023.

Almeida T.I.R., Souza Filho C.R., Rosseto R. 2006. ASTER and Landsat ETM+ Images Applied to Sugarcane Yield Forecast. International Journal of Remote Sensing, 27: 4057-4069.

Almeida T.I.R, Juliani C., Mantovani W., Perez-Aguilar A. 2007a. Comunidades florestais como indicadores geobotânicos: o caso da mineralização aurífera do Grupo Serra do Itaberaba, Guarulhos, São Paulo. Revista Brasileira de 
Geociências, 37:37-49.

Almeida T.I.R., Perrotta M.M., Souza Filho C.R., Santos M.G.M. dos. 2007b. Geobotânica por sensoriamento remoto no mapeamento geológico de região recoberta por floresta amazônica de terra firme: uma avaliação metodológica na região do Vale do Guaporé (RO). In: INPE, Simp. Bras. Sensoriamento Remoto, 13, Anais, p. 1951-1958.

Botrel R.T., Oliveira Filho A.T., Rodrigues L.A., Curi N. 2002. Influência do solo e topografia sobre as variações da composição florística e estrutura da comunidade arbóreo-arbustiva de uma floresta estacional semidecidual em Ingaí, MG. Revista Brasileira de Botânica, 25:195-213.

Brasil. 1979. Projeto RADAM: folha SD-20 Guaporé. Levantamento de Recursos Naturais, DNPM/CPRM, Vol.19, 369 p.

Brooks R.R. 1972. Geobotany and Biogeochemistry in Mineral Exploration. New York, Harper \& Row, 290 p.

Cannon H.L. 1960. Botanical prospecting for ore deposits. Science, 132: 591-598.

Cannon H.L. 1971. The use of plant indicators in ground water surveys, geologic mapping, and mineral prospecting. Taxon, 20:227-256.

Chikishev A.G. 1965. Plant Indicators of Soils, Rocks and Subsurface Waters. New York, Consultants Bureau, 210 p.

Collins W., Chang S.H., Raines G., Canney F., Ashley R. 1983. Airborne biogeophysical mapping of hidden mineral deposits. Economic Geology, 78:737-749.

CPRM, SERVIÇO GEOLÓGICO DO BRASIL 2007. Projeto Aerogeofísico Sudeste de Rondônia (RO-MT). Magnetometria e Gamaespectrometria. Código 1068. Base de metadados AERO disponível em: http://www.cprm.gov. br/aero/aero.htm. Acessado em 02/07/2007 (Relatório do aerolevantamento: LASA). ENGENHARIA e PROSPECÇÕES S.A. \& PROSPECTORS Aerolevantamentos e Sistemas Ltda. 2006. Projeto Aerogeofisico Sudeste de Rondônia. Relatório Final do Levantamento e Processamento dos Dados Magnetométricos e Gamaespectrométricos. Rio de Janeiro. Ministério de Minas e Energia, Secretaria de Geologia, Mineração e Transformação Mineral, CPRM - Serviço Geológico do Brasil, Relatório Final, 27 vol., Texto e Anexos (Mapas).

Dickson B.L. \& Scott K.M. 1997. Interpretation of aerial gamma-ray surveys-adding the geochemical factors. AGSO Journal of Australian Geology \& Geophysics, 17:187-200.

EARTH REMOTE SENSING DATA ANALYSIS CENTER (ERSDAC) 2006. Aster product guide. Release Note. Disponível em: http://www.gds.aster.ersdac.or.jp/gds www2002/service_e/release_e/set_release_ecrs.html. Acessado em 02/07/2007.

Godoy J.R.L. 2001. Estrutura e composição específica da Mata Atlântica secundária de encosta sobre calcário e filito no Parque Estadual Turístico do Alto Ribeira, Iporan$g a, S P$. Dissertação de Mestrado, Instituto de Biociências, Universidade de São Paulo, 112 p.

Green A. A., Berman M., Switzer P., Craig M. D. 1988. A transformation for ordering multispectral data in terms of image quality with implications for noise removal. IEEE Transactions on Geoscience and Remote Sensing, 26:65-74.

Horler D.N.H., Barber J., Barringer A.R. 1980. Effects of heavy metals on the absorbance and reflectance spectra of plants. International Journal of Remote Sensing, 1:121-136.
INSTITUTO BRASILEIRO DE GEOGRAFIA E ESTATÍSTICA (IBGE) 1992. Manual técnico da vegetação brasileira. Rio de Janeiro, IBGE.

INSTITUTO BRASILEIRO DE GEOGRAFIA E ESTATÍSTICA (IBGE) 2004. Mapa de vegetação do Brasil. Disponível em: ftp://geoftp.ibge.gov.br/mapas/tematicos/mapas_murais/vegetacao.pdf. Acessado em 29/11/2007.

INSTITUTO BRASILEIRO DE GEOGRAFIA E ESTATÍSTICA Online (IBGE). 2007. Banco de dados georreferenciado, recursos naturais, folha SD-20: vegetação. Disponível em: ftp://geoftp.ibge.gov.br/mapas/banco_dados_georeferenciado_recursos_naturais/latlong/SD-20/ vegetacao.exe. Acessado em 29/11/2007.

Martelet G., Truffert C., Tourlière B., Ledru P., Perrin J. 2006. Classifying airborne radiometry data with agglomerative hierarchical clustering: a tool for geological mapping in context of rainforest (French Guyana). International Journal of Applied Earth Observation and Geoinformation, 8:208-223.

Milton N.M. 1983. Use of reflectance spectra of native plant species for interpreting airborne multispectral scanner data in the east Tintic Mountains, Utah. Economic Geology, 78:761-769

Mouat D.A. 1982. The response of vegetation to geochemical conditions. In: International Symposium on Remote Sensing for Exploration Geology, Proceedings, $2^{\text {nd }}$ Thematic Conference, p. 75-84.

Raines G.L., Offield T.W., Santos E.S. 1978. Remote-sensing and subsurface definition of facies and structure related to uranium deposites, Powder River Basin, Wyoming. Economic Geology, 73:1706-1723.

Ricardo F. \& Rolla A. (org) 2005. Mineração em Terras Indígenas na Amazônia brasileira. São Paulo, Instituto Socioambiental (ISA), $179 \mathrm{p}$.

Rizzotto G.J. 2006. Geologia da Folha Pimenteiras (SD.20.X.D), região limítrofe Brasil-Bolívia. In: SBG, Congr. Bras. Geol., 43, Anais, p. 189.

Sztutman M. E. \& Rodrigues R. R. 2002.O mosaico vegetacional numa área de floresta contínua da planície litorânea, Parque Estadual da Campina do Encantado, PariqueraAçu, SP. Revista Brasileira de Botânica, 25:161-176.

Talvitie J. 1979. Remote sensing and geobotanical prospecting in Finland. Bulletin of the Geological Society of Finland, 51:63-73.

Ustin S.L., Smith M.O., Jacquemoud S., Verstraete M.M., Govaerts Y.M. 1999. Geobotany: Vegetation Mapping in Earth Sciences. In: Rencz A.N. (ed.) Remote Sensing for Earth Sciences: Manual for Remote Sensing. 3rd ed., New York, John Wiley \& Sons Inc., vol. 3, p. 189-247. Disponível em: http://www.cstars.ucdavis.edu/papers/html/ ustinetal1998b. Acessado em 14/02/2008

Wilford J.R., Bierwirth P.N., Craig M.A. 1997. Application of airborne gamma-ray spectrometry in soil/regolith mapping and applied geomorphology. Journal of Australian Geology \& Geophysics, 17:201-216.

Manuscrito ID 8255

Submetido em 04 de julho de 2007 Aceito em 20 de junho de 2008 Sistema eletrônico de submissão 